\title{
Michael Tooley and the Jolly Nasty Conclusion
}

\section{JOHN HARRIS}

ABSTRACT Some recent powerful and persuasive arguments seem to imply that a world of people with lives that are barely worth living is preferable to a world which contains fewer people all of whom have extremely satisfying lives. This 'repugnant conclusion' is clearly to be rejected if possible-but is it possible? Many attempts to reject or avoid it have failed. One of the latest, by Michael Tooley, looked promising but the present essay argues that this attempt has also failed.

It is always exciting when a philosopher believes he has solved a problem, particularly when it is one of the most intractable and interesting of the problems of contemporary moral philosophy. In his recent book Abortion and Infanticide [1] Michael Tooley believes that he has done just this.

The problem arises for Tooley because an important part of his general position involves the claim that there is a moral symmetry between acts and omissions. This in turn raises the question of whether, if it is wrong to kill someone, it is equally wrong to refrain from bringing someone into existence. It is this latter problem that has proved so engaging and that Tooley believes himself finally to have laid to rest.

The essence of the problem is crystallised in two arguments developed by Derek Parfit [2], both of which are discussed at length by Tooley. The first is the 'mere addition argument'; the second, to which this leads, is the argument from the 'repugnant conclusion'. Briefly, the repugnant conclusion is "that for any world containing a finite number of people leading extremely satisfying lives, there is a better world which contains a larger number of people, but each of whom leads a life that is just barely worth living" [3]. The conclusion is repugnant because we are forced to regard a world of people with lives barely worth living as preferable to a world which contains fewer people, but people who have extremely satisfying lives. But why are we forced to this conclusion? This can be shown by a rehearsal of Tooley's formulation of the 'mere addition argument'.

Let $A$ be a world containing 100 people, each enjoying 100 units of happiness. Let $\mathbf{A}+$ be a world that differs from $\mathrm{A}$ only in the addition of some extra happy people. These additional people do not affect in any way the 100 people who exist both in $A$ and $A+$. In short $A+$ contains the 100 people who exist in world A enjoying precisely the same level of happiness-100 units-together with let us say, 100 additional people, each enjoying 10 units of happiness. Finally let world B contain the same 200 people as are in the world $A+$ but where each person enjoys 60 units of happiness [4]. 
Parfit suggests that if one compares these three worlds, one can hold that $\mathrm{A}+$ is not worse than A since the only difference between the two worlds is that $\mathrm{A}+$ contains some additional people leading lives that are still worth living, and the addition of these people involves no loss to the first 100 but mere addition. Moreover although the second 100 in A+ may be said to be relatively deprived, the alternative for them is non-existence and so the worse off group may be said to benefit from the inequality whereas the better off group do not suffer from it-this being the case it may be said that $A+$ is a world that is not worse than $A$. Now if we compare world $B$ with $A+$ it seems plausible to hold that $B$ is better than $A+$, since the same number of people are on average better off than in $A+$, and there is no inequality or relative deprivation. So, if $\mathbf{B}$ is better than $\mathrm{A}+$ and $\mathrm{A}+$ is not worse than A, B must be better than $\mathrm{A}$. This argument can, in Tooley's words "be repeated indefinitely, generating a sequence of better and better worlds, containing more and more people at even lower levels of happiness" [5] until one arrives at the repugnant conclusion.

The importance of all this for Tooley's own concerns is not perhaps immediately clear, but it is simply that the repugnance of the repugnant conclusion is not a sufficient objection to the soundness of the argument that leads to it. And this argument implies, among other things, that a world with more people who have lives that are worth living is better than a world with fewer such lives; and if this is right it implies that there is a moral obligation to bring people into existence or a moral obligation not to refrain from so doing. Now Tooley wants to deny this, and in order to make plausible this denial he has to combat the mere addition argument. I cannot here hope to do justice to his ingenious combativeness in this cause, but the success of his battle depends upon his making plausible and successfully defending some general moral principles.

Tooley describes his endeavour as an attempt "to set out very general ethical principles that imply that the fact that an action will produce additional persons, or additional persons with certain properties-such as that of leading very satisfying lives-cannot be a right-making characteristic" [6]. If Tooley can sustain principles that have this effect he will have avoided the mere addition argument and the repugnant conclusion and also saved us all from an ethic which could commit us to almost unlimited procreation. Given the importance of the principles and the work they are to do, Tooley spends very little space (only one and a half pages) establishing the principles in question. It is clear that they are designed ad hoc to perform a particular task and their justification will simply be that they perform this task, that they otherwise mesh with our general moral intuitions, and that they entail no otherwise unacceptable consequences.

Briefly the principles Tooley chooses are the following.

[A]n action may be prima facie wrong either because it violates an obligation one has with respect to some individual, or because it brings it about that there is an individual with respect to whom one has an obligation that cannot be satisfied... (and) that every individual has a right to a life worth living, and a right to an equal chance of having those things that make possible a satisfying life... [7].

A first point to note is that these principles, even if correct, do not entirely avoid the mere addition argument, as Tooley is himself well aware:

There are two cases that need to be distinguished: that where redistribution is possible and that where it is not. First the case where redistribution is not 
possible. There is not on the present approach any objection to producing additional people no matter how low their level of happiness, provided that one is doing the best that one can, and that their lives are not ones that are not worth living. Second, the case where redistribution is possible. We produce let us say, a group of minimally happy serfs. Their existence benefits those of us who would have existed anyway, and they are glad they were conceived, since the only real alternative for them would be non-existence: .... The present approach implies that it would be prima facie wrong to add such a group... to the world [8].

However, the principles Tooley has chosen to protect himself (and us) from the undesirable consequences of an ethic of unlimited procreation and from the repugnant conclusion, are themselves unable to resist conclusions which if not repugnant are at any rate jolly nasty.

In elaborating the defence of his three principles, Tooley invites us to consider the cases of three women, all of whom are interested in having five children.

Amy is pregnant for the first time and if nothing is done she will give birth to a normal child but will be unable to have any more children. On the other hand, if an operation is performed, this will result in her giving birth to a defective child, but will also enable her to produce four more children, all of whom will be normal. Amy decides to have the operation. Becky is not pregnant. If she becomes pregnant immediately, she will give birth to a normal child, but will be unable to have any more children. If she waits three months, her first child will be defective, but the next four will be normal. Becky decides to wait three months. Finally the case of Cathy. She is told that if she has five children, all of them will be normal at birth but that she should expect that one of them will catch a disease that will make it defective. Cathy has five children and one of them does contract the disease [9].

Briefly, Tooley believes, and believes his principles show, that Amy and Becky both violate their firstborn's right to an equal chance of enjoying those things that make for a satisfying life, and that therefore Amy and Becky act wrongly. Cathy on the other hand gives all of her children an equal chance of being normal, so that although it is certain that one of them will become defective, she does not wrong that child in the way that Amy and Becky wrong theirs.

This is a crucial conclusion for Tooley because it seems to him that it offers a refutation of an otherwise plausible argument advanced by Richard Sikora [10] to the effect that there is a moral obligation to produce people whose lives are worth living. And if Sikora is right then we are inexorably led to the repugnant conclusion. Sikora's argument, paraphrased by Tooley, goes like this:

If it is wrong in itself to create a wretched person, but not to risk doing so when there is a sufficiently good chance of producing a happy person, must it not be the case that the production of a happy person is a positive consideration that outweighs the risk of bringing someone wretched into existence? And how is this to be explained except on the assumption that the creation of happy people is prima facie obligatory, or, at least, good in itself [11]? 
Tooley believes that the plausibility of Sikora's argument rests on a confusion between the following two propositions:

(1a) Provided that $p$ is sufficiently small, it is not in itself morally wrong to perform an action that will lead, with probability $p$, to the existence of a person who is certain to be thoroughly wretched, and, with probability (1-p) to the existence of some other person who is certain to be happy,

and

(1b) Provided that $p$ is sufficiently small, it is not in itself morally wrong to perform an action that will lead to the existence of a person who will be, with probability $p$, thoroughly wretched, and, with probability (1-p), happy [12].

Once this confusion is brought out we can see that while (1a) does show that bringing happy people into existence cannot be an event with no moral significance and hence leads to the repugnant conclusion, (lb) does not. Tooley believes that reflection upon Amy's and Becky's predicaments in the light of his principles shows why (1a) is unacceptable. The same reflection on Cathy's choice shows that (1b) is both acceptable and that it is innocent of the repugnant conclusion.

But is it plausible to regard the cases of Amy and Becky on the one hand, and that of Cathy on the other, as morally separable? Is it unexceptionable to suppose that Cathy's action is not morally comparable to that of Amy or Becky? Surely each of the three mothers has acted in ways that are morally isomorphic, and if this is right then the moral distinction between (1a) and (1b) collapses and Tooley's principles can neither save us from an ethic of unbridled reproduction nor from the repugnant conclusion.

If we look for the basis of the distinction between Amy and Becky on the one hand and Cathy on the other we will find that the ground for Cathy's superiority is simply that she doesn't know which one of her children will be defective under any prior identifying description-like being 'the firstborn'. But can this make a moral difference? After all, each woman has chosen to have five children knowing that one will be defective. Each has judged the production of one defective child a price worth paying for the survival of four normal children. But now why is there a moral difference between the price that Cathy (or rather Cathy's child) pays for the four normal children and that paid by Amy and Becky (and their defective children)? Tooley believes that the moral difference between the cases, given that one child is going to be defective in each of them, is that in Cathy's case, her actions are "compatible with not only its being the case that all her children have an equal chance of being normal, but with all of her children having as good a chance of being normal as one can have in the environment in question" [13].

But Tooley has avoided the repugnant conclusion only to generate one that is at best jolly nasty.

The jolly nasty conclusion is this: suppose as a result of a massive radiation leak it becomes clear that any children conceived anywhere in the world will be normal at birth but that $99 \%$ of them will subsequently become defective. The only alternative is for $1 \%$ of the women to take a drug which will render their offspring defective but which will enable enough antidote to be manufactured from their blood to protect not only their own subsequent offspring but the remaining $99 \%$ of the population as well. Tooley's principles show, by analogy with Cathy's case, that if the women of the world adopt the first course they will not only have done nothing wrong but they will have acted in a way which is clearly morally preferable to the second alternative.

The first alternative involves no wrongdoing because their choice to procreate 
regardless is not only compatible with its being the case that all their children have an equal chance of being normal (albeit an equally small chance) but that all their children have as good a chance of being normal as one can have in the environment in question.

The second choice, of producing a small number of defective children from whose mother's blood an antidote can then be manufactured in large quantities, is ruled out because it violates Tooley's "principle of the right to an equal opportunity" [14].

Thus Tooley's principles entail that it can be morally preferable to choose to make over $99 \%$ of the next generation defective rather than to choose to make less than $1 \%$ of them defective.

Correspondence: John Harris, Department of Education, University of Manchester, Oxford Road, Manchester M13 9PL, England.

\section{NOTES}

[1] Michael Tooley (1983) Abortion and Infanticide (Oxford, Oxford University Press). I don't of course mean to imply that this is the only argument in Tooley's excellent book, nor that he has not solved other problems.

[2] See Derex Parfit (1984) Reasons and Persons (Oxford, Oxford University Press), Chapters 17-19. Tooley uses earlier versions of these arguments and I have quoted Tooley's own formulations of them throughout.

[3] TOOLEY, op. cit., p. 250.

[4] Ibid., p. 263.

[5] Ibid., p. 264.

[6] Ibid., p. 270.

[7] Ibid., pp. 283, 284.

[8] Ibid., pp. 282-283.

[9] Ibid., pp. 276-277.

[10] R. I. SIKORA (1975) Utilitarianism: the classical principle and the average principle, Canadian fournal of Philosophy, 5. I use Tooley's formulations of Sikora's argument throughout.

[11] TOOLEY, op. cit., p. 276.

[12] Ibid., pp. 278, 279 (my emphasis). The proviso that the probability be small plays no role in the present argument since in all of Tooley's examples the probability of producing defective children is assumed to be as high as it can be.

[13] Ibid., p. 278.

[14] Ibid. 